\title{
Dementia-Related Products on an e-Commerce Platform
}

\author{
Benjamin K P Woo, MD \\ University of California, Los Angeles, Sylmar, CA, United States
}

\section{Corresponding Author:}

Benjamin K P Woo, MD

University of California, Los Angeles

14445 Olive View Drive

Sylmar, CA, 91342

United States

Phone: 17472103830

Email:bkpwoo@gmail.com

\begin{abstract}
Dementia is a neurocognitive disorder, which affects older adults. There are currently no medication treatments available to cure dementia, but a number of biomedical technologies could be useful in assisting patients with dementia. With the continued growth of electronic commerce (e-commerce), online shopping for aging and health-related products will only continue to increase. Using the Tmall marketplace as an example, the purpose of this viewpoint is to describe the current trends of dementia-related products and devices available on an e-commerce platform. Feedback and critiques in the form of consumer reviews should be used to improve the design of dementia-related products. Online medical product consumers, however, must be vigilant about the effectiveness and risks of these biomedical devices.
\end{abstract}

(JMIR Biomed Eng 2020;5(1):e17514) doi: 10.2196/17514

\section{KEYWORDS}

consumer review comments; dementia; e-commerce; biomed; technology; devices; biomedical engineering

Electronic commerce (e-commerce) has allowed patients and their caregivers to directly buy health products and medical devices from a seller over the internet. The largest of these online corporations include Alibaba, Amazon, and eBay. Tmall.com, a Chinese-language business-to-consumer (B2C) website operated by Alibaba in China, has approximately 260 million monthly visits from potential consumers and ranks number 9 among all websites in the e-commerce and shopping category [1]. A 2015 report from the Chinese government highlighted that while $59 \%$ of items sold online were genuine or of good quality, at least $40 \%$ of online goods sold were either counterfeits or of bad quality [2]. Tmall.com may eventually offer a reliable marketplace for consumers to purchase authentic medical products and devices; however, the sheer number of sellers on the $\mathrm{B} 2 \mathrm{C}$ platform makes eliminating fake or counterfeit health products or biomedical devices from the Tmall marketplace difficult.

Dementia-also known as neurocognitive disorder-involves a constellation of symptoms including apathy, behavioral changes, confusion, and the impairment of executive functions [3-5]. A systematic review found that the estimated number of people with dementia in China was 9.2 million in 2010 [6]. There are currently no medication treatments available to cure dementia or to alter its progressive course [7-9]. However, there are a number of biomedical engineering technologies that can assist patients with dementia. For example, GPS locator devices could alert family members when someone with dementia wanders away from home [10]. With the continued growth of e-commerce and the worldwide popularity of online shopping for aging and health-related products, all biomedical engineers and health professionals should be prepared to further understand such trends. Therefore, the keyword dementia (老年痴呆症) was searched on Tmall.com to provide a viewpoint on these trends of online shopping for dementia-related products.

On Tmall, an online marketplace for Chinese-language consumers at home and abroad to make purchases, there were a total of 1038 dementia-related products identified on November 29, 2019. Among these dementia-related items, 788 (75.92\%) were books, $137(13.20 \%)$ were medications or supplements, $65(6.26 \%)$ were bracelets or wristbands, 42 $(4.05 \%)$ were dementia toys, and $6(0.57 \%)$ were biomedical devices. Of the 6 biomedical technologies, 4 were GPS-tracking Smart Watches for older adults, and 2 were transcranial magnetic stimulators.

There were no reviewer comments for the 2 transcranial magnetic stimulators; however, the consumer ratings for the 4 
Smart Watches were relatively positive (4.8 out of 5.0). Some reviewer comments (translated from Chinese to English) were included to understand how older Chinese adults may feel about technology for dementia. A reviewer wrote, "Very suitable for elderly with visual impairments and falls... Voice control is necessary [for elderly]." Another reviewer commented, "Easy to use, can make phone calls... but GPS can miss by 5 meters indoor." An older adult reviewer stated, "My children will know my whereabouts, and I feel more emotionally secured because I know my children are on the other side of the watch."

On the other hand, using online shopping for buying biomedical devices is not without risks. A recent small study found that transcranial magnetic stimulation (TMS) may temporarily improve memory; however, the study did not examine which areas of the brain should be targeted with stimulation nor how effective the treatment could be [11]. In addition, the Food and Drug Administration (FDA) of the United States has recently rejected the first TMS device to be used for treating symptoms of dementia, as the clinical trial for this device failed to demonstrate efficacy [12]. This particular TMS device is registered and classified as a Class II medical device by China's National Medical Products Administration (NMPA); however, the Tmall marketplace failed to point out that no assessment concerning the safety and efficacy of this device has been conducted for patients with dementia. Online shopping from the Tmall marketplace may become commonplace, but consumers and patients from China and abroad must be vigilant about the safety and effectiveness of these non-FDA or non-NMPA approved biomedical devices. The Tmall marketplace must ensure sellers are not overstating the medical device benefits and, more importantly, use algorithms to get rid of fake or unregulated health products targeting vulnerable older adults and their caregivers.

Future work should examine how to incorporate online consumer review comments on dementia-related products, especially feedback and critiques from older adult users, to improve the design of biomedical engineering technologies. Excellence in design may only be achieved when biomedical engineers incorporate the needs of all stakeholders, that is dementia patients, their caregivers, and their families. Reviewer comments may serve as a proxy for quality improvement. However, in addition to the likelihood of purchasing online biomedical engineering products that could be fraudulent or counterfeit, this viewpoint highlights the issues of safety and effectiveness of dementia-related products purchased from the Tmall marketplace. Online medical product consumers need to look beyond the cost savings and focus on the effectiveness and risks of such medical treatments. This viewpoint demonstrates how widespread these dementia products and medical devices are in a Chinese-language e-commerce marketplace, but a limitation to keep in mind is the possibility of fake reviews, fake comments, or even fake transactions on the Tmall marketplace. Nevertheless, Alibaba has used machine learning to lower search rankings for stores engaged in false transactions. In addition, in 2017, the Chinese government sentenced a merchant associated with generating fake reviews and transactions to approximately 6 years in prison [13].

\section{Conflicts of Interest}

None declared.

\section{References}

1. SimilarWeb. Top sites ranking for e-commerce And shopping > marketplace in the world URL: https://www.similarweb.com/ top-websites/category/e-commerce-and-shopping/marketplace

2. Jourdan A. Reuters. 2015 Nov 02. Over 40 percent of China's online sales counterfeit, shoddy: Xinhua URL: https://tinyurl. com/rvc4waa

3. Woo BKP, Harwood DG, Melrose RJ, Mandelkern MA, Campa OM, Walston A, et al. Executive deficits and regional brain metabolism in Alzheimer's disease. Int J Geriatr Psychiatry 2010 Nov;25(11):1150-1158. [doi: 10.1002/gps.2452] [Medline: 20069587]

4. Woo BK. Dementia health promotion for Chinese Americans. Cureus 2017 Jun 29;9(6):e1411 [FREE Full text] [doi: 10.7759/cureus.1411] [Medline: 28856076]

5. Woo BK. Family history and its relationship with dementia stigma beliefs among Chinese Americans. Geriatr Gerontol Int 2017 Jan;17(1):122-125. [doi: 10.1111/ggi.12686] [Medline: 26694867]

6. Chan KY, Wang W, Wu JJ, Liu L, Theodoratou E, Car J, Global Health Epidemiology Reference Group (GHERG). Epidemiology of Alzheimer's disease and other forms of dementia in China, 1990-2010: a systematic review and analysis. Lancet 2013 Jun 08;381(9882):2016-2023 [FREE Full text] [doi: 10.1016/S0140-6736(13)60221-4] [Medline: 23746902]

7. Lam NHT, Woo BKP. YouTube as a new medium for dementia education among Chinese Americans. Community Ment Health J 2019 Oct 22. [doi: 10.1007/s10597-019-00493-7] [Medline: 31641910]

8. Lam NH, Woo BK. Digital media recruitment for fall prevention among older Chinese-American individuals: observational, cross-sectional study. JMIR Aging 2018 Nov 01;1(2):e11772 [FREE Full text] [doi: 10.2196/11772] [Medline: 31518249 ]

9. Cheng TY, Liu L, Woo BK. Analyzing Twitter as a platform for Alzheimer-related dementia awareness: thematic analyses of tweets. JMIR Aging 2018 Dec 10;1(2):e11542 [FREE Full text] [doi: 10.2196/11542] [Medline: $\underline{\text { 31518232] }}$

10. Topfer L. GPS locator devices for people with dementia. CADTH Issues in Emerging Health Technologies 2016 Aug 31. [Medline: 27809428] 
11. Nilakantan AS, Mesulam M, Weintraub S, Karp EL, VanHaerents S, Voss JL. Network-targeted stimulation engages neurobehavioral hallmarks of age-related memory decline. Neurology 2019 May 14;92(20):e2349-e2354. [doi: 10.1212/WNL.0000000000007502] [Medline: 30996057]

12. Strickland E. IEEE Spectrum. 2019 Mar 19. First device to treat Alzheimer's is up for approval by the FDA URL: https:/ /spectrum.ieee.org/the-human-os/biomedical/devices/the-first-device-to-treat-alzheimers-is-up-for-approval-by-the-fda

13. Davis K. Sixth Tone. 2017 Jun 22. In judicial first, man imprisoned for fake Taobao reviews URL: https://www.sixthtone.com/ news/1000374/in-judicial-first \%2C-man-imprisoned-for-fake-taobao-reviews

\section{Abbreviations}

B2C: business-to-consumer

e-commerce: electronic commerce

FDA: Food and Drug Administration

NMPA: National Medical Products Administration

TMS: transcranial magnetic stimulation

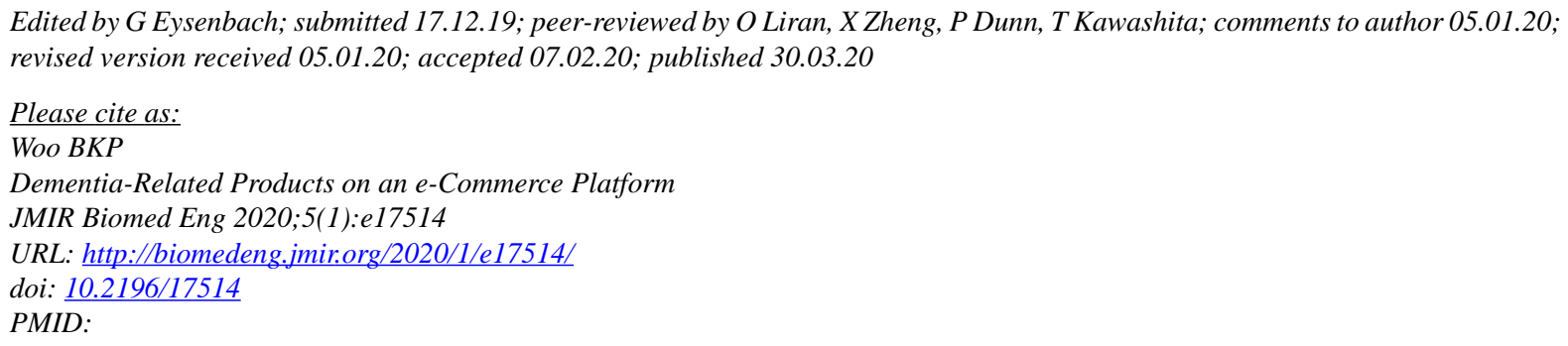

CBenjamin K P Woo. Originally published in JMIR Biomedical Engineering (http://biomedeng.jmir.org), 30.03.2020. This is an open-access article distributed under the terms of the Creative Commons Attribution License (https://creativecommons.org/licenses/by/4.0/), which permits unrestricted use, distribution, and reproduction in any medium, provided the original work, first published in JMIR Biomedical Engineering, is properly cited. The complete bibliographic information, a link to the original publication on http://biomedeng.jmir.org/, as well as this copyright and license information must be included. 